\title{
Amateur Astronomy in Poland: Past and Present
}

\author{
Katarzyna Turaj
}

Wyzsza Szkola Pedagogiozna, ul. Podchorazych nr. 2, PL-30084 Krakow, Poland

\section{Introduction}

Amateur astronomy in Poland has its own history dating from the 17th century to the present day. Before the 17 th century, the term "amateur astronomer" loses its meaning. Otherwise we might pose the rather paradoxical question: "Was Copernicus an amateur?" and probably have to give the answer: "Yes, he was an amateur, being first a priest, a physician and a lawyer." Let us leave him in peace and instead turn to more undoubted amateurs. The history can be divided into two general periods: before and after the creation of the Polish Amateur Astronomical Society, PAAS (Polskie Towarzystwo Milosników Astronomii - PTMA). Here we present 16 Polish amateur astronomers who contributed to astronomy from the 17th to the 20th centuries, except Jan Heweliusz - the greatest - who is discussed elsewhere (1). All are selected from a much larger group, the selection being made in accordance with the rules described in the very useful and practical "Criteria for identifying an astronomer as an amateur", formulated by Tom Williams a few years ago and presented here (2). There is also a short history and current information about the PAAS. Finally, we summarize successes and failures of amateur astronomy in Poland and put some general questions about its future.

\section{Great Individuals from Urania's Host}

Let us begin with a lady. Maria Kunicka (1620-1664) is considered to be the first Polish woman astronomer. She was born at Swidnica and well-known for her erudition and beauty. Her most important work was Urania propitia sive tabulae astronomicae (Byczyn, 1654, by Johann Seyffertus the printer). There are probably some individual volumes in the oldest European libraries, but alas not in Poland.

Stanisław Rola-Lubieniecki (1623-1675), was an Arian minister (bishop), interested in explaining comet appearances in a scientific way. He wrote the 3-volume work Theatrum Cometicum (Amsterdam, 1667) about comets from "The Flood to $1665 "$ ".

Józef Aleksander Jablonowski (1712-1777), Voivode of Nowgród and a prince. He wrote a historical and astronomical work to advance Copernicus' theory $D e$ 
astronomiae ortu atque progressu et de telluris motu (Rome, 1763). In 1774 he founded the scientific society called "Societas Jablonoviana".

Jerzy Kunowski (1786-1846), a lawyer born in Silesia, but it is not known whether of Polish or German origin. He studied the surfaces of the Moon and the planets, and also calculated the rotational period of Mars. There is a crater on the Moon named Kunovsky after him ( $400 \mathrm{~km}$ SE of Copernicus).

Hercules Dembowski (1812-1881), a sailor born in Milano as son of a Polish emigrant and an Italian aristocrat. He founded an observatory on the side of Mount Vesuvius and observed double stars there; estimating their positions was his main interest (3). His findings were published in Astronomische Nachrichten. Dembowski was awarded the Copley Medal of the Royal Society of London (1878) and the planetoid 349 was called Dembowska from his name. One can also find a crater Dembovsky on the Moon.

Jan Walery Jedrzejewicz (1835-1887). A physician, who appears to be the greatest Polish amateur astronomer of the last two centuries. He founded an observatory at Plonsk, where he made most of his observations of double stars. He measured positions of 16 comets and made systematic observations of sunspots and occultations of stars by the Moon. Besides publishing papers in Astronomische Nachrichten, he wrote a handbook of astronomy called Kosmografia (Warszawa, 1886).

Zygmunt Laskowski (1841-1928), a professor of medicine. His most important contribution was the discovery of Nova Aquilae 1918.

Adam Ostoja-Ostaszewski (1860-1934). This strange person could be called the "enfant terrible" of Polish amateur astronomy, although he was also called "the Leonardo of Wzdów" because of his aviation inventions. After building an observatory he published the mad, but fascinating work, Le vrai système du monde, putting in it his fictitious cosmology "proving" that the Sun is situated inside the Earth, and that one only sees its image in the mirror-like sky.

Feliks Przypkowski (1872-1951). A physician interested in time-keeping and clocks. He gathered a large collection of sundials of many types and ages. The collection forms the unique Museum of Clocks in Jedrzejow.

Antoni Wilk (1878-1939), a teacher of physics who became a professional astronomer and a renowned comet hunter. He discovered the following comets: $1925 \mathrm{k}, 1929 \mathrm{~d}, 1930 \mathrm{c}$, and $1937 \mathrm{c}$. He was awarded four medals by the Astronomical Society of the Pacific.

Tadeusz Rakowiecki (1878-1965), a practising physician who was self-taught in astronomy. He used to say that he had not become a professional astronomer because of the need to serve people more directly. He turned down an offer to stay at the university as a professor of astronomer. He wrote 24 papers on the calculation of orbits, double stars and eclipse theory, and also published the astronomy handbook Ways of planets and comets (Warszawa, 1928).

Antoni Rybarski (1889-1972) was an engineer interested in amateur telescopes. He built a $350-\mathrm{mm}$ Newtonian and a 150 -mm telescope combined with a camera for photography. He also invented a telescope with a metal mirror (PL patent No. 424261959). 
Feliks Rapf (1891-1972). A teacher of physics interested in education and the popularization of astronomy. He organized many courses in astronomy and published papers and notes in Urania and the Physics at School magazines.

Jerzy Pokrzywnicki (1882-1974). A lawyer, who engaged in scientific research into meteorites. He described many meteorites in his 60 papers.

Władysław Lis (1911-1980), a janitor at the Lubomir Observatory (in the Beskidy Mountains). He discovered a comet known as Kaho-Kozik-Lis (1936 III) and was awarded the J.A. Donhoe Medal of the Astronomical Society of the Pacific.

Edward Szeligiewicz (1924-1959), an architect who observed meteors, solar and lunar eclipses, and variable stars. He left two interesting manuscripts: Atlas of Eclipsing Binaries and Small Atlas of the Moon.

\section{The Polish Amateur Astronomical Society}

Polish amateur astronomy began a new phase in 1919 when several keen youngsters from secondary schools started the small "Amateur Astronomical Circle" with about 20 members. They published four issues of a magazine Uranja, printed by lithography. In 1921, the Circle was legalized and changed its name to "Polish Society of Friends of Astronomy", being officially founded by adults. When it began it had about 50 members. That number increased to about 3500 today. Before World War II, members of PFSA organized many lectures and sky demonstrations for the general public. The quarterly Urania published astronomical information and data, and popular articles under the title of "Mysteries of the Universe". During the War, in an occupied country, the PSFA did not exist as a formal organization. It was a time when even professional astronomers worked as amateurs. As for young amateurs, two groups continued their activity: in Dobra Woda (editing reports and the list of objects observed), and in Sporysz (printing the clandestine magazine Mathematics and Astronomy Monthly, and organizing an expedition to watch a lunar eclipse in 1942. This seems to be an interesting case, proving that even astronomy can be underground. (4)

Amateur astronomers reactivated their Society in 1948, but had started even earlier by organizing some popular lectures on Polish radio in 1945, and by publishing the first post-war issue of Urania in 1946. Thenceforward the association was named the Polish Amateur Astronomical Society (PAAS).

\section{The Activities of the PAAS}

The society acts in the form of clubs in various towns, these are equipped with instruments according to their own resources - ranging from just binoculars to even a small observatory. The clubs are supervised by Headquarters, which undertakes general work, such as: training observers; coordination of amateur research; editorial activities and the distribution of astronomical publications. The clubs arrange lectures, star parties, film or discussion evenings, and keep small astronomical libraries. Camps and courses for beginners or advanced observers are arranged by Headquarters, paying particular attention to the education of the young. Urania is published 
regularly, while the Scientific Supplement to Urania - the astronomical reports other leaflets, charts, and calendars are published from time to time. Observers work in six sections: Variable Stars; History; Meteors and Meteorites; Positions and Occultation Timing; Solar, Sky Patrol. The most active nowadays seems to be the Positions and Occultation Timing Section, which is a member of I.O.T.A. This is significant, because the Section of the PAAS was the organizer of the European Symposium on Occultation Projects in 1986. The Solar Section, called "The Sunflowers" is also active, but has recently split away from the PAAS and called itself the Solar Observers' Society.

The Sections cooperate directly with professional astronomers, partly because of the need for some help and advice, and partly because of the need to publish findings in scientific journals. It should be stressed that the PAAS, although an amateur society, has never closed its door to professional astronomers. On the contrary, many professional astronomers, especially those fond of popularization, are active and devoted members of PAAS, and devote a lot of work to Headquarters and the Scientific Council.

\section{The Present, and Some Questions About the Future}

The PAAS now consists of 30 clubs. Several are still very active, but there are others that are slowly dying, because of the small number of active members. Does this mean that astronomy is losing its attractiveness? Many letters from youngsters that arrive every day at the PAAS Headquarters show that it does not. Headquarters do their best to answer questions either by post or by organizing courses. But many young people find the courses disappointing. Lectures cannot compete with amazing scientific programmes often shown on television. Some old forms of amateur activity should be changed to modern ones. On the other hand, the development of amateur astronomy today depends greatly on technical equipment - if we assume that making observations is the main way for amateurs to make a real contribution to astronomy. Overall achievements are hardly limited by the level of technology, and the gap between highly-, and poorly-developed countries is growing as time goes by.

The PAAS continues the tradition of great amateur astronomers in a country that is at a low level of technology. But there is also the other aim of amateur astronomy, which appears somewhat less attractive. There the aim is to be a link between high-level professional science and ordinary life, transmitting information from the very exclusive group of scientists to the general public. That purpose with a little help from the modern mass-media - could probably be developed in any country in the world.

1. Iwaniszewska, C., “Johannes Hevelius: Polish seventeenth-century brewer and astronomer", contributed paper presented at this Colloquium

2. Williams, T., "Criteria for identifying an astronomer as an amateur", contributed paper presented at this Colloquium

3. P. Couteau, "The history of amateurs' contribution to the study of double stars", invited paper presented at this Colloquium

4. [See also, Walter, K., "Astronomy in Poland during the Second World War", J. Brit. astron. Assoc., 97 (5), 270, (1987) - Eds.] 